EESTI NSV TEADUSTE AKADEEMIA TOIMETISED. XIV KOIDE

FOOSIKA-MATEMAATIKA- JA TEHNIKATEADUSTE SEERIA. 1965, NR. 1

ИЗВЕСТИЯ АКАДЕМИИ НАУК ЭСТОНСКОИ ССР. ТОМ ХІV СЕРНЯ ФИЗИКО-МАТЕМАТИЧЕСКИХ И ТЕХНИЧЕСКИХ НАУК. 1965, № 1

\title{
ЭКСПЕРИМЕНТАЛЬНОЕ ИССЛЕДОВАНИЕ СТАТИСТИЧЕСКОГО ХАРАКТЕРА РАДИАЦИОННОГО ПОЛЯ В ПОСЕВЕ КУКУРУЗЫ
}

При решении проблемы управления фотосинтезом сельскохозяйственных посевов большое значение приобретает изучение раднационного поля в посевах. Посев представляет собой среду с довольно сложной структурой, где рассеивающие и поглощающие радиацию элементы (листья, стебли и т. д.) имеют большие размеры по сравненню с высотой посева, расположены не совсем хаотично (наблюдается механическое взаимодействие между отдельными элементами), а индикатрисы рассеяния резко отличаются от шаровой и ориентированы не хаотично. Это значит, что свойства посевов не совпадают с общепринятыми представлениями о мутной среде. Но, с другой стороны, мутная среда довольно хорошо поддается теоретической трактовке, для нее разработаны общие уравнения переноса радиации и при известных граничных условиях радиационные потоки в любой точке теоретически предсказуемы. Сказанное делает использование модели мутной среды привлекательным и для случая растительного покрова. Ю. Росс $\left[{ }^{1,2}{ }^{2}\right]$ решил уравнение переноса в приближении Шварцшильда для растительного покрова, и полученные им результаты представляют большой интерес.

Посев, как мутную среду, экспериментально изучали Х. Тооминг и Х. Нийлиск $[3,4]$. Ими были получены эмпирические законы для описания ослабления радиационных потоков в растительном покрове и найдена величина поглощенного потока, что дало возможность вычислить интенсивность фотосинтеза посева [4]. Эти результаты нмеют большое значенне для решения общей проблемы управления фотосинтезом посевов.

Ясно, что наши представления о радиационном поле растительного покрова не могут ограничиться моделью мутной среды, а для их дальнейшего развития нужны более детальные экспериментальные данные. Приведенный Х. Нийлиском метод вычисления фотосинтеза посева довольно прост и не требует сложных экспериментов для получения исходных данных для практических расчетов. В этом смысле он является лерспективным. Но для оценки точности этого метода необходимы данные о действительном радиационном поле в посевах.

Детальные исследования радиационного режима растительного покрова в литературе почти не встречаются. Визнер [5] первым обратил внимание на присутствие внутри растительности световых потоков, имеющих различные направления. . Первые измерения были выполнены А. Зейболдом $\left[{ }^{6}, 7\right]$ при помощи фотоэлемента, ориентированного под разными углами. Эти работы были продолжены О. Хэртелом [8, 9], который пользовался фотоэлементом в сочетании с разными стеклянными светофнльтрами 
и получил более подробные данные о радиационном поле в некоторых ценозах, в том числе и в посеве кукурузы.

Радиационное поле в растительном покрове очень сложно, поэтому его обычно представляют с помощью осредненных данных. Однако при более детальном его изучении средние значения радиационных параметров не содержат достаточного колнчества информации. Полная информация о случайной величине содержится в ее функции распределения. Впервые результаты своих измерений, сделанных в лесу, в виде

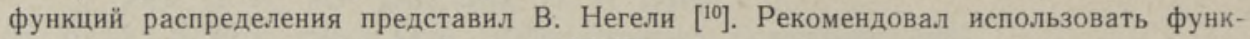
ции распределения также В. Алексеев [11, $\left.{ }^{2}\right]$.

Настоящая работа является попыткой дальнейших исследований в этом направлении. Нами измерялись интенсивности и потоки радиации в посеве кукурузы в различных направлениях, причем учитывались не их средние значения, а функции плотности вероятности (дифференциальные функции распределения). Измерения были проведены в ходе комплексной экспедиции по проблеме «Фотосинтез» летом 1963 г. в Иыгева (Эст. ССР).

Измерения проводились на кукурузном поле ('Буковина-3') с интервалом между рядами посева 60 см и густотой посева 274000 растений на гектар. Приведенные далее данные относятся к периоду развития, когда высота посева достигла 200 см.

Измерения проводились с помощью спектрофотометра, специально сконструированного для этой цели. При измерении интенсивности угол зрения приемника был равен $5^{\circ}$, интерференционные фильтры имели максимумы пропускания на длине волны 482 и 558 ммк. Датчиком служил селеновый фотоэлемент. При измерении потоков на прибор надевалась насадка из сдвоенного молочного стекла $\left[{ }^{13}\right]$. В этом случае селеновый фотоэлемент работал без интерференционных фильтров. Спектральная чувствительность селенового фотоэлемента большей частью находится в области ФАР (от 380 до 710 м.мк). В. Гуляевым [14] вычислено, что при измерении отраженной от растительности ФАР с помощью селенового фотоэлемента, градуированного по прямому излучению, погрешность не превышает 2-3\%. В прошедшей через растительность радиации важную роль играют прямая радиация и рассеянная радиация неба, следовательно, в этом случае погрешность еще уменьшается. Таким образом, можно считать, что селеновый фотоэлемент без интерференционных фильтров измеряет фотосинтетически активную радиацию.

Спектрофотометр был установлен на каретку и вместе с ней двигался на тросах в растительном покрове. Длина пути передвижения равнялась 5 м. Система тросов была установлена так, чтобы спектрофотометр двигался между рядами посева. В плоскости, перпендикулярной к направлению движения, оптическая ось спектрофотометра могла находиться под разными углами $\vartheta$ к вертикали. Получились разрезы радиационного поля в плоскости, перпендикулярной к рядам. Вся система могла находиться на разной высоте в посеве. Размеры спектрофотометра вместе с кареткой - $10 \times 10 \times 10$ см $^{3}$.

Выход спектрофотометра был подключен к статистическому анализатору конструкции автора. Записывались гистограммы плотности вероятности интенсивностей и потоков. Для получения одной гистограммы требовалось 2 мин.

Падающий на растительный покров спектральный поток радиации измерялся спектрофотометром конструкции Х. Нийлиска $\left[{ }^{15}\right]$. Все результаты измерений приведены к единичному падающему потоку. На рисунках гистограмм распределения потоков ФАР в посевах единицей по осп абсцисс служит относительный поток в посеве 


$$
I_{\Phi}^{*}=\frac{I_{\Phi}}{Q_{\Phi}}
$$

тде $I_{\Phi}-$ измеренный в посеве поток $Ф$ АР; $Q_{\Phi}-$ падающий в это время на посев поток ФАР.

Ось ординат калибрована в единицах плотности вероятности так, чтобы функция распределения нормировалась к единице.

Гистограммы распределения интенсивностей тоже рассчитывались на единицу падающего потока

$$
i_{\lambda}^{*}=\frac{i_{\lambda}}{Q_{\lambda}}
$$

тде $i_{\lambda}-$ измеренная монохроматическая интенсивность; $Q_{\lambda}-$ падающий монохроматический поток суммарной радиации той же длины волны $\lambda$.

При условии, что падающий поток равен единице, интенсивность, соответствующая яркости, равномерно распределенной по небу, равняется $1 / \pi$. Так как при облачной погоде яркость неба примерно равномерна (с точностью $20-30 \%$ ), это условие было использовано при выборе масштаба оси абсцисс гистограмм распределения интенсивностей. Среднему месторасположению максимума просвечивания облачного неба соответствует интенсивность $1 / \pi$. Такая градуировка очень груба, но она не имеет принципиального значения и сделана только для того, чтобы над посевом выполнялось условие

$$
\int_{2 \pi} i^{*}(\vec{r}) \cos \vartheta d \Omega=Q_{\lambda}=1 .
$$

Масштаб оси ординат выбран в соответствии с условием нормирования гистограммы к единице.

На рис. 1 приведена типичная картина распределения интенсивностей $\left(i i_{\lambda}^{*}\right)$ в посеве кукурузы на разных высотах и в разных направлениях при полной облачности.

Рассмотрим динамику изменения распределений интенсивностей.

Над посевом наблюдается только одно значение интенсивности, соответствующее яркости неба в данном направлении. На гистограммах распределения интенсивностей имеется соответственно только один столбик (на рисунке не приведены). При погружении спектрофотометра в растительность возникает «хвост» в направлении меньших интенсивностей (квадрат a1). Вскоре появляется и второй максимум, соответствующий наиболее вероятной яркости листьев (б1). Из рисунка видно, что яркость листьев верхних уровней в зеленом свете при облачном небе составляет примерно $10 \%$ от яркости неба. Максимум, соответствующий наиболее вероятной яркости листьев, возрастает при увеличении глубины (81); максимум, соответствующий просвечиванию неба, уменьшается и, наконец, исчезает (21). В глубине посева контраст между небом и листьями увеличивается и на высоте 80 см яркость листьев составляет только $3-4 \%$ от яркости неба. В картине распределения интенсивности в синем свете $(\lambda=482$ ммк), сравнивая с распределением, измеренным в зеленом свете, существенных различий нет. Поэтому специального рисунка для этого случая мы не приводим. Можно лишь 


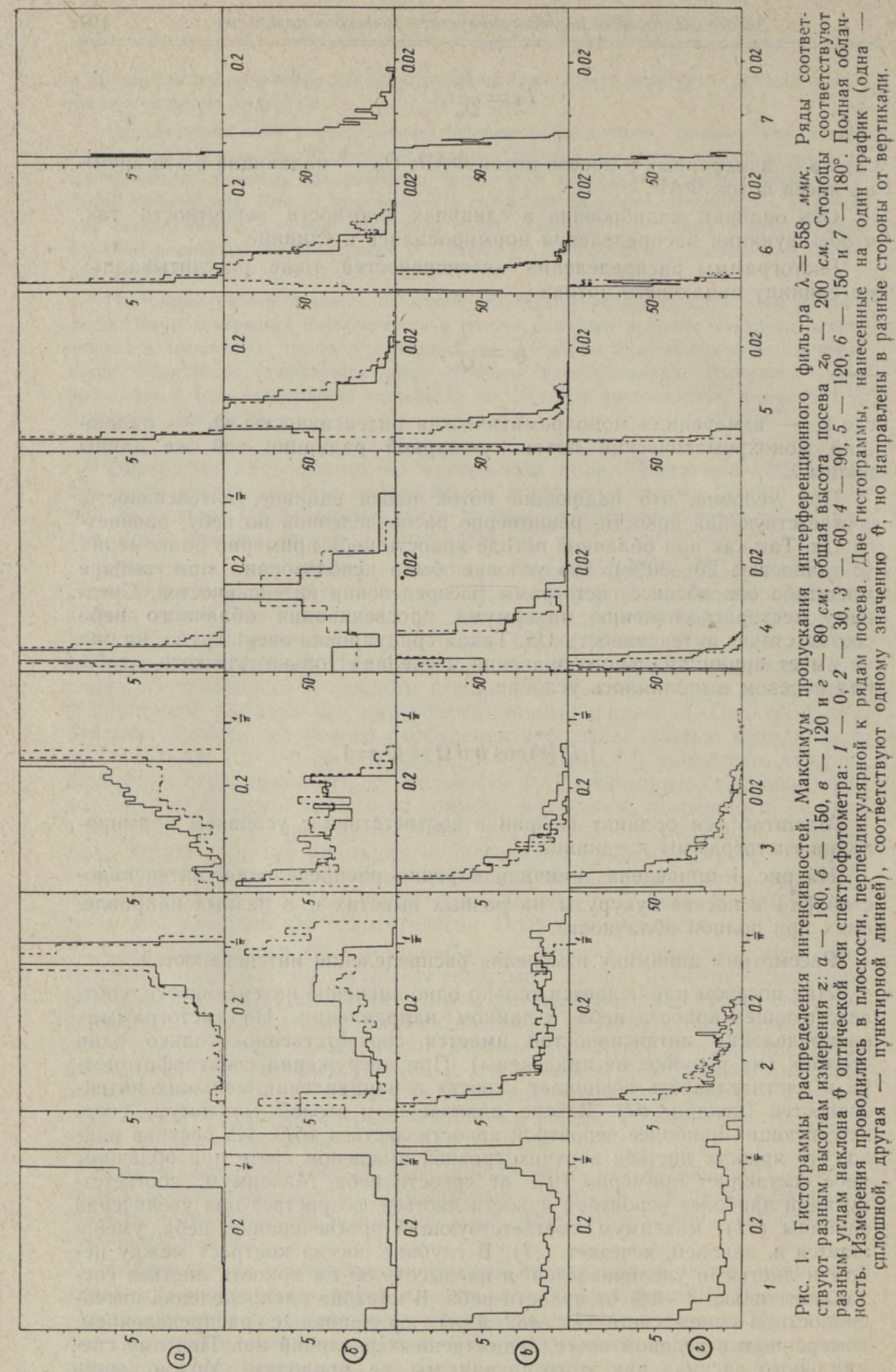


отметить, что контраст между небом и листьями в синем свете еще больше, так как поглотительные свойства зеленых листьев в синей части спектра увеличиваются.

Такая динамика изменения функций распределения примерно повторяется при всех углах наклона в верхней полусфере (рис. 1, столбцы 2 и 3). Разница только в том, что чем больше $\vartheta$, тем быстрее протекает процесс возникновения второго максимума и исчезновения первого. Это происходит за счет удлинения оптического пути луча зрения в растительном покрове (пропорционально $\sec \vartheta$ ).

В нижней полусфере максимума, соответствующего просвечиванию неба, конечно, не наблюдается (столбцы 4-7; масштаб в левой нижней части рис. 1 изменен в 10 раз). В общем можно отметить, что при $\vartheta>90^{\circ}$ функции распределения имеют ассиметричный вид: их «хвост». направлен в сторону бс́льших интенсивностей.

Наименьшие интенсивности наблюдаются при $\vartheta=180^{\circ}$.

Функции распределения при одинаковых $\vartheta$, но в разные стороны от вертикали, довольно хорошо совпадают. Это свидетельствует о симметричности поля интенсивностей в посеве кукурузы при облачном небе (точнее - при изотропном падающем на посев потоке). Несовпадение максимумов просвечивания неба в некоторых случаях $(62,82)$ обусловлено неодинаковой яркостью неба в соответствующих направлениях.

На рис. 2 приведена картина распределения интенсивностей при ясном небе $(\lambda=558$ ммк). Обозначения на рис. 2 соответствуют тем же высотам измерения и углам наклона, что и на рис. 1. Посев тот же. Масштабы осей гистограммы также остались без изменения.

Динамика изменения функций распределения интенсивностей в зависимости от высоты и угла наклона при ясной погоде похожа на динамику изменения при облачном небе. Только структура падающего потока в этом случае совсем другая, что и влечет за собой некоторые изменения в форме функций распределения. Бо́льшая часть $(70-80 \%)$ энергии падающего потока сосредоточена в прямом излучении Солнца, остальная часть составляет рассеянную радиацию неба. При падающем потоке, равном единице, яркость небосвода в направлениях, далеких от Солнца, в 4-5 раз меньше яркости небосвода при полной сблачности (взятого тоже при единичном падающем потоке). Только в направлениях, близких к направлению на Солнце, яркость неба больше яркости облачного неба.

Из рис. 2 видно, что местонахождение максимума просвечивания неба сильно зависит от направления оптической оси спектрофотометра и в большинстве случаев отличается в $4-5$ раз меньшей интенсивностью, чем в случае облачного неба. Местонахождение максимума, соответствующего наивероятнейшей яркости листьев, примерно то же, что и в случае облачного неба. Из этого следует, что поле рассеянной растительностью радиации мало зависит от структуры падающего потока. При ясной погоде в зеленом свете листья могут с некоторой вероятностью быть ярче неба (рис. 2, квадраты $a 1,61, a 2,62,82$ и др.).

При углах наклона $\vartheta>90^{\circ}$ функции распределения интенсивностей при ясной и облачной погоде почти одинаковы. В случае ясной погоды функции распределения имеют более длинные «хвосты», что свидетельствует о наличии ярких бликов прямого излучения.

В синей части спектра картина примерно такая же. Контрасты между листьями и небом получаются бо́льшими, так как небо в синем свете ярче, а листья темнее, чем в зеленом. Листьев, которые были бы ярче неба, в синем свете нет. Последнее обстоятельство может служить основой при конструировании нового прибора. 


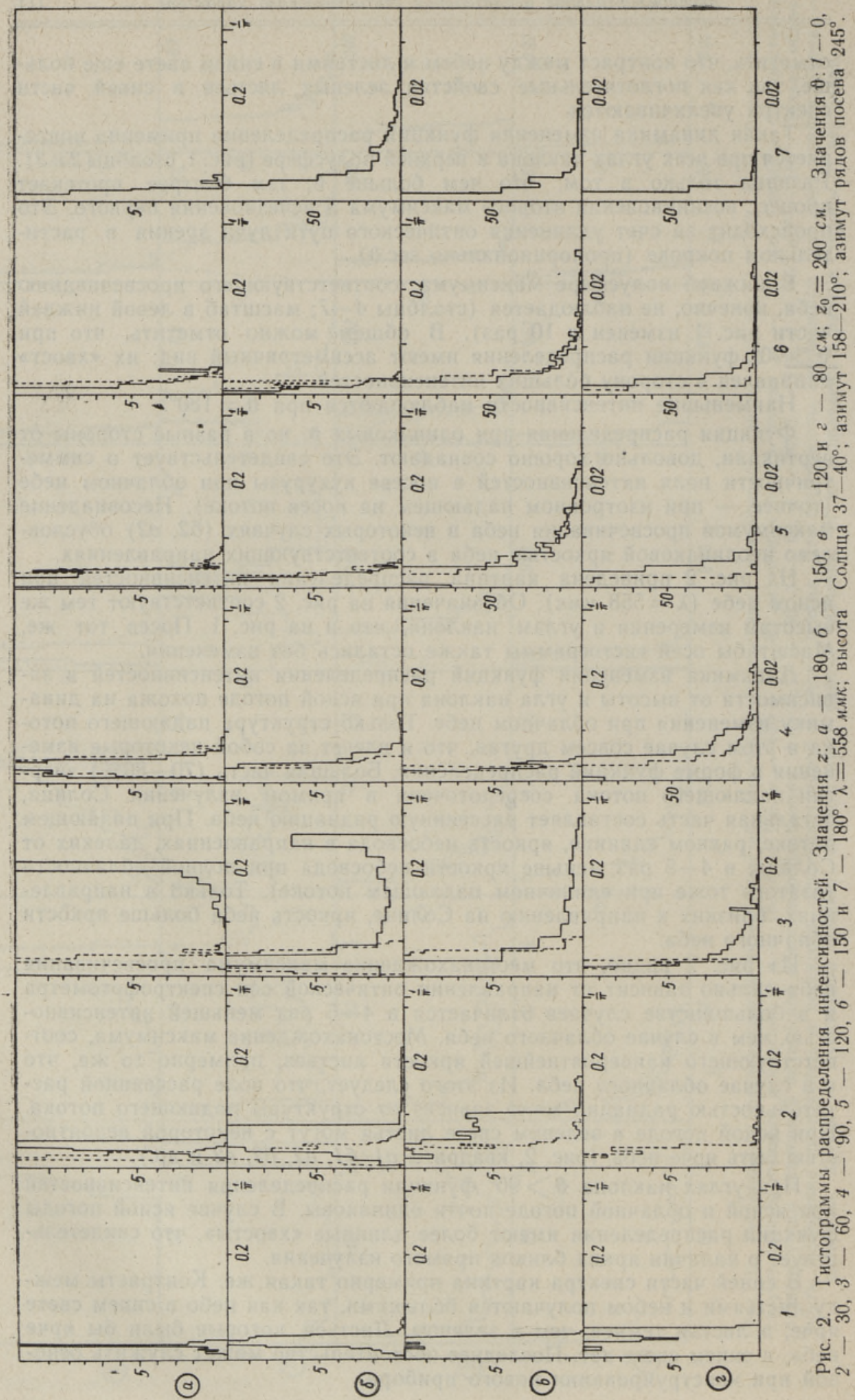


Прямая радиация Солнца играет в энергетическом отношении решающую роль при фотосинтетической деятельности посевов. Поэтому важно знать пропускание посевов относительно прямой радиации в зависимости от высоты Солнца. Довольно хорошие результаты при измерении пропускания прямой радиации дает метод Е. Лопухина [16], усовершенствованный позднее Х. Нийлиском [17]. Идея метода заключается в том, что по прямолинейному отрезку под растительностью измеряется либо на глаз [16], либо автоматически [ $\left.{ }^{17}\right]$ относительная доля пути, освещенного солнечными пятнами. Измерения удобны, но зависят от погоды и от местонахождения Солнца на небосводе. В северных районах Солнце вообще не достигает высот, необходимых для географических обобщений.

Поток рассеянной радиации неба, которая падает на данный уровень внутри растительного покрова, не взаимодействуя с листьями растений, при пасмурной погоде приносит большинство, при ясной погоде $10-20 \%$ всей лучистой энергии. Для непосредственного измерения этого потока пока прибора не существует. Единственным методом является измерение просвечивания неба в отдельных направлениях и последующее интегрирование.

То обстоятельство, что в синем свете контрасты между небом и листьями довольно велики при любой погоде, позволяет сконструировать прибор для измерения просвечивания неба. Он должен представлять собой чувствительный в синей части спектра светоприемник с очень узким углом зрения (не более $0,5^{\circ}$ ), установленный на движущейся каретке. Выход датчика подключается к интегральному дискриминатору с регулируемым порогом. При помощи такого прибора можно в короткий срок определить просвечивание неба (ясно, что это то же самое, что и пропускание прямой радиации) во многих направлениях. Главное, что измерения не зависят от погодных условий.

Распределение потока ФАР $I_{\Phi}^{*}$ как случайной величины образуется в результате суммарного действия бесконечного числа случайных элементарных потоков $i_{\Phi}^{*} d \Omega\left(i_{\Phi}^{*}-\right.$ интенсивность, $\Omega-$ телесный угол). При полной облачности следовало бы ожидать, что каждый элементарный поток $i_{\Phi}^{*} d \Omega$ имеет малый вес в общем потоке и несмотря на то, что распределения $i_{\Phi}^{*}$ далеки от нормального, распределение $I_{\Phi}^{*}$ выходит нормальным (предполагается, что распределение инстенсивности в области ФАР примерно похоже на измеренное распределение $i_{\lambda}^{*}$ при $\lambda=558$ ммк). На рис. 3 представлены гистограммы распределения $I$ * при полной облачности. Измерения сделаны на тех же высотах и под теми же углами наклона, что и на рис. 1. Посев тот же.

Динамика изменения функции распределения $I_{\Phi}^{*}$ отличается от динамики изменения распределения $i$ *. Максимума просвечивания неба нет. Все распределения имеют один максимум на месте наиболее вероятного $I_{\Phi}^{*}$ и этот максимум постепенно, по мере погружения уровня измерения в посев, продвигается в сторону меньших потоков (рис. $3, a$, $\sigma, 6,2)$. То же самое наблюдается при увеличении угла наклона $\vartheta$ на фиксированном уровне (рис. $3,1,2,3$...). Что касается нормальности, то кривые распределения $I_{\Phi}^{*}$ более похожи на нормальные, чем кривые распределения $i_{\lambda}^{*}$ (один максимум), но считать их вполне нормальными нельзя. Наблюдается заметная асимметрия на верхних и нижних уровнях. Видно, что для количественной оценки статистического материала недостаточно. 


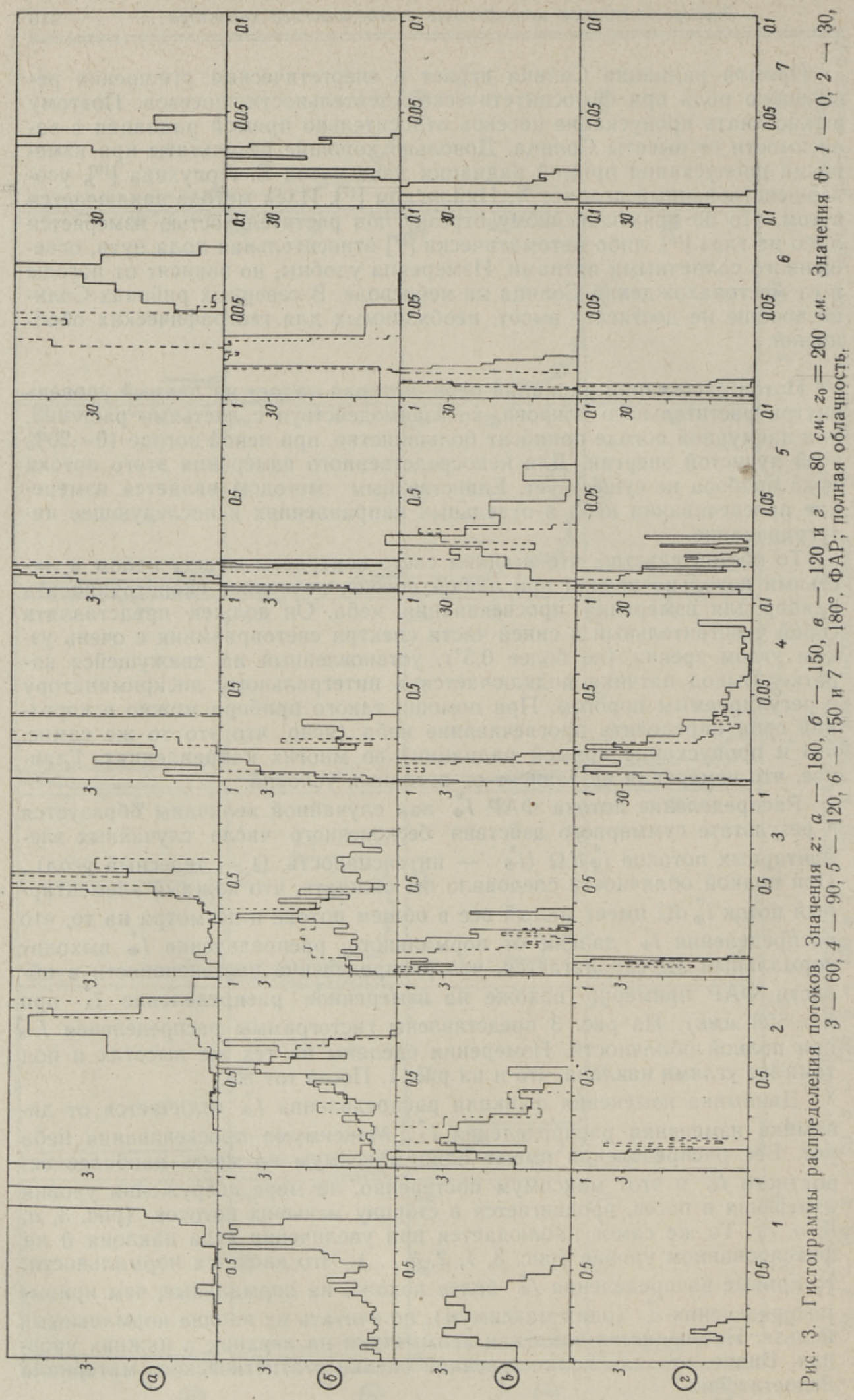




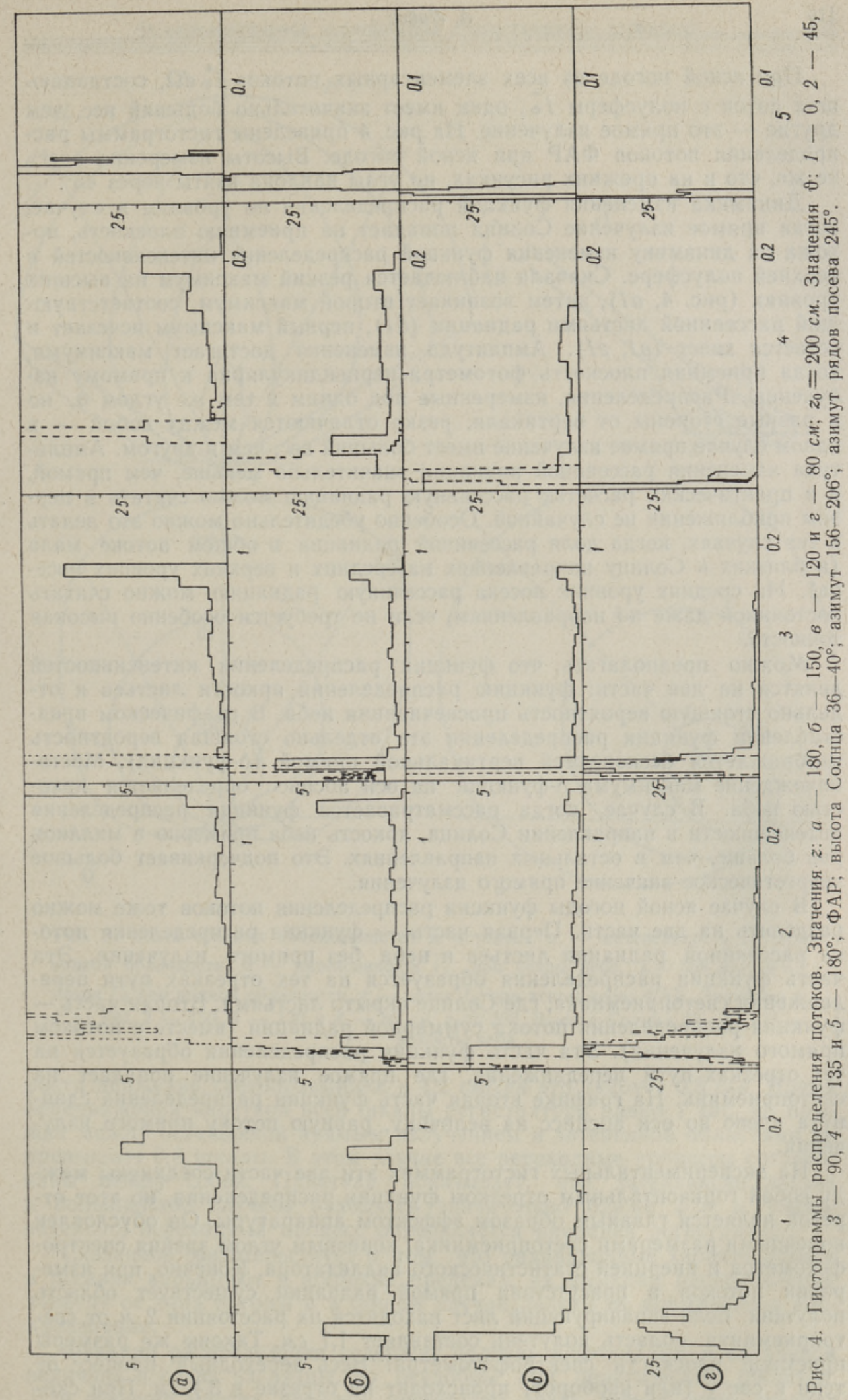


При ясной погоде из всех элементарных потоков $i_{\Phi}^{*} d \Omega$, составляющих поток с полусферы $I_{\Phi}^{*}$, один имеет значительно больший вес, чем другие - это прямое излучение. На рис. 4 приведены гистограммы распределения потоков ФАР при ясной погоде. Высоты измерения здесь те же, что и на прежних рисунках, но углы наклона взяты через $45^{\circ}$.

Динамика изменения функций распределения по уровням в случае, когда прямое излучение Солнца попадает на приемную плоскость, похожа на динамику изменения функций распределения интенсивностей в верхней полусфере. Сначала наблюдается резкий максимум на высших уровнях (рис. $4, a 1$ ), затем возникает второй максимум, соответствующий рассеянной листьями радиации (б1), первый максимум исчезает и остается хвост $(81,21)$. Амплитуда изменения достигает максимума, когда приемная плоскость фотометра перпендикулярна к прямому излучению. Распределения, измеренные под одним и тем же углом $\vartheta$, но в разные стороны от вертикали, резко отличаются между собой - в одном случае прямое излучение имеет больший вес, чем в другом. Амплитуда изменения рассеянной радиации значительно меньше, чем прямой, и в практических расчетах рассеянную радиацию можно считать в первом приближении не случайной. Особенно убедительно можно это делать в тех случаях, когда доля рассеянной радиации в общем потоке мала (в близких к Солнцу направлениях на средних и верхних уровнях посева). На средних уровнях посева рассеянную радиацию можно считать постоянной даже по направлениям, если не требуется особенно высокая точность.

Можно предполагать, что функции распределения интенсивностей делятся на две части: функцию распределения яркости листьев и отдельно стоящую вероятность просвечивания неба. В графическом представлении функции распределения эта отдельно стоящая вероятность изображается бесконечной вертикальной прямой (ס-функция). Местонахождение максимума $\delta$-функции на оси абсцисс определяется яркостью неба. В случае, когда рассматривается функция распределения интенсивности в направлении Солнца, яркость неба примерно в миллион раз больше, чем в остальных направлениях. Это подчеркивает большое энергетическое значение прямого излучения.

В случае ясной погоды функции распределения потоков тоже можно разделить на две части. Первая часть - функция распределения потока рассеянной радиации листьев и неба без прямого излучения. Эта часть функции распределения образуется на тех отрезках пути передвижения светоприемника, где Солнце скрыто листьями. Вторая часть функция распределения потока суммарной радиации (вместе с потоком прямого излучения). Эта часть функции распределения образуется на тех отрезках пути передвижения, где прямое излучение попадает на светоприемник. На графике вторая часть функции распределения сдвинута влево по оси абсцисс на величину, равную потоку прямого излучения.

На экспериментальных гистограммах эти две части соединены между собой горизонтальным отрезком функции распределения, но этот отрезок является главным образом эффектом аппаратуры. Он обусловлен конечными размерами светоприемника, конечным углом зрения спектрофотометра и инерцией статистического анализатора. Конечно, при измерении потоков в присутствии прямой радиации существует область полутени. Если экранирующий лист находится на расстоянии $2 \mu$ от светоприемника, область полутени составляет 1,7 см. Таксвы же размеры приемной плоскости спектрофотометра. Весь переходный процесс от тени к свету (или наоборот) происходит на отрезке в 3,4 см. При ско- 

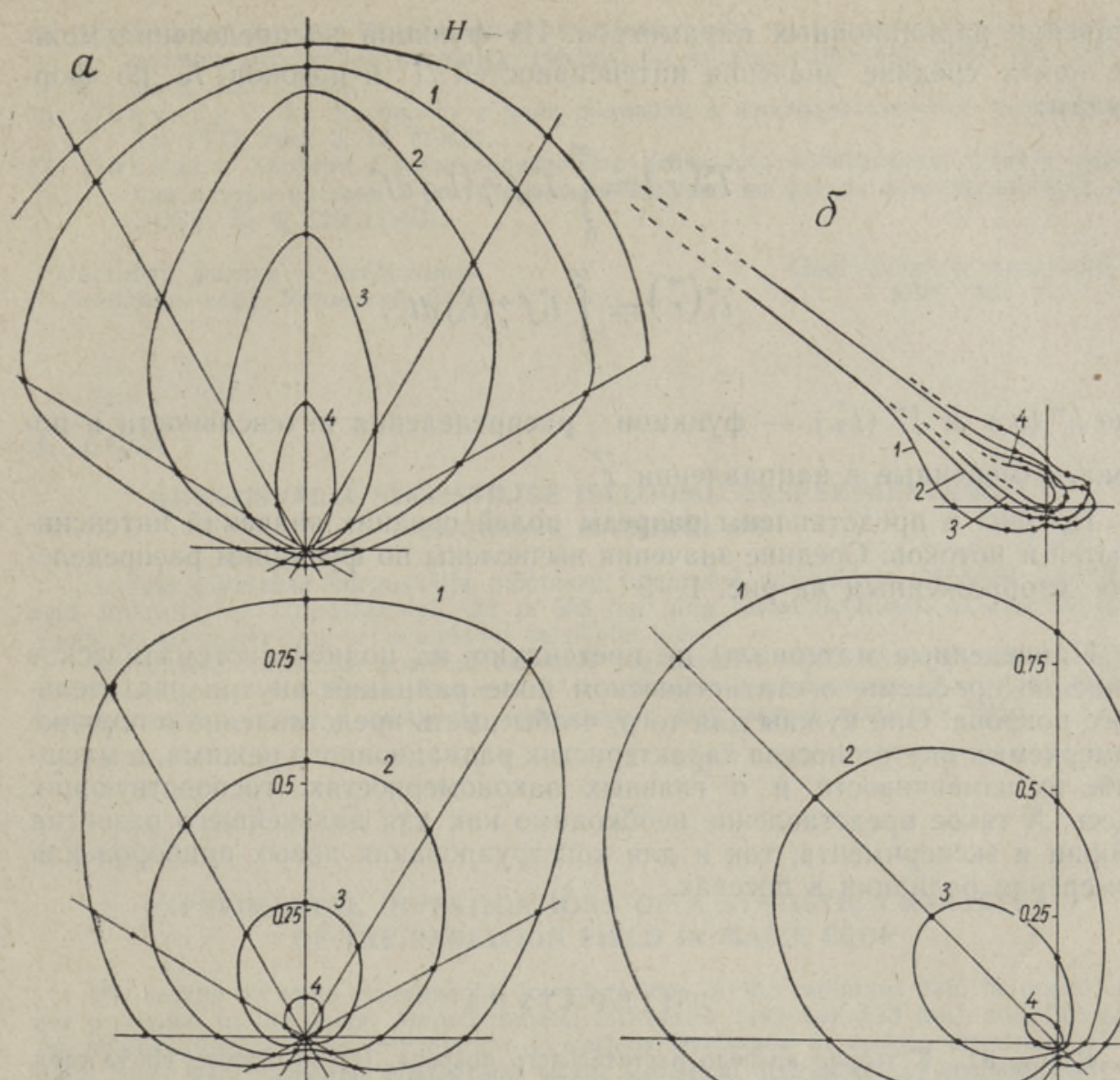

B

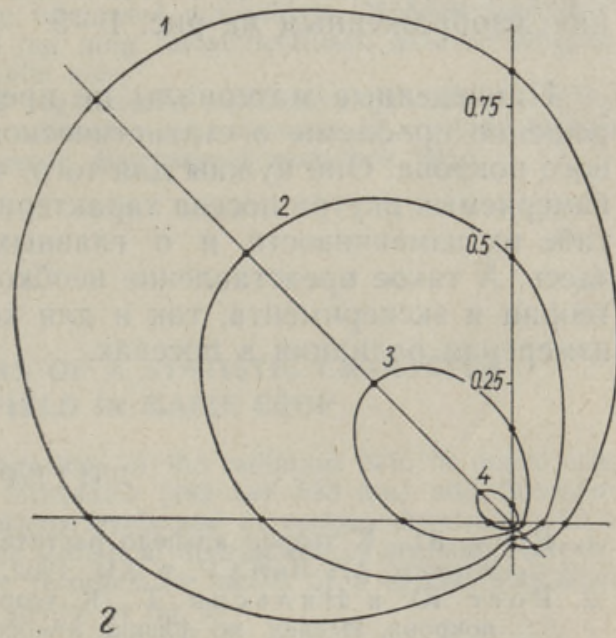

Рис. 5. Поля средних интенсивностей и потоков. $a-$ интенсивность $\bar{i}_{\lambda}^{*}$ при полной облачности, $\sigma-$ интенсивность $\bar{i}_{\lambda}^{*}$ при ясном небе, $\lambda=558$ ммк; в поток $\bar{I}_{\Phi}^{*}$ при полной облачности, г - поток $\bar{I}_{\Phi}^{*}$ при ясном небе; ФАР. Значения $z$ : $1-180,2-150,3-130$ и $4-80 \mathrm{~cm}, z_{0}=200$. Высота Солнца $36-40^{\circ} ; H-$ яркость неба.

рости движения светоприемника в 4,2 см/сек это требует 0,8 сек. Время передвижения кареткой всей шкалы регистратора равно 1 сек, но прыжок между освещенной прямым излучением и затененной областями не превышает 0,8 шкалы. В этом случае все переходные процессы согласованы между собой. Практика показывает, что затеняющие листья в большинстве случаев находятся значительно ближе 2 и, следовательно, переходный процесс определяется инерцией регистратора.

Сказанное свидетельствует о том, что радиационные характеристики в посевах варьируют в широких пределах, их функции распределения зависят от типа погоды и в общем случае далеки от нормального распределения.

Функции распределения содержат полную информацию о случайной величине и очень наглядны, но неудобны при практических расчетах. Для решения многих проблем достаточно знать только поле средних 
значений радиационных параметров. Из функций распределения можно найти средние значения интенсивностей $\vec{i}_{\lambda}^{*}$ и потоков $\vec{I}_{\Phi}^{*}$ по формулам:

$$
\begin{aligned}
& \bar{I}_{\Phi}^{*}(\vec{r})=\int_{0}^{\infty} I_{\Phi}^{*} f \vec{r}_{r}\left(I_{\Phi}^{*}\right) d I_{\Phi}^{*} \\
& \bar{i}_{\lambda}^{*}(\vec{r})=\int_{0}^{\infty} i_{\lambda}^{*} f \vec{r}_{r}\left(i_{\lambda}^{*}\right) d i_{\lambda}^{*},
\end{aligned}
$$

где $f_{r}\left(i_{\lambda}^{*}\right)$ и $f_{r}\left(I_{\Phi}^{*}\right)$ - функции распределения интенсивности и потока, измеренные в направлении $\vec{r}$.

На рис. 5 представлены разрезы полей средних значений интенсивностей и потоков. Средние значения вычислены по функциям распределения, изображенным на рис. $1-5$.

Приведенные материалы не претендуют на полное систематическое решение проблемы о статистическом поле радиации внутри растительного покрова. Они нужны для того, чтобы иметь представление о порядке измеряемых внутри посева характеристик радиационного режима, о масштабе их изменчивости и о главных закономерностях, господствующих здесь. А такое представление необходимо как для дальнейшего развития теории и эксперимента, так и для конструирования новых приборов для измерения радиации в посевах.

\section{Л ИТЕРА Т У РА}

1. Р осс Ю., К теории альбедо растительного покрова, Научн. сообщ. Ин-та геол. н геогр. АН ЛитССР, т. ХІІ, 1962, 151.

2. Росс Ю. и Нильсон Т., К теории радиационного режима растительного покрова, Исслед. по физике атмосферы ИФА АН ЭССР, № 4, 42 (1963).

3. Т ооминг Х. и Р осс Ю., Радиационный режим посева кукурузы по ярусам и описывающие его приближенные формулы, Исслед. по физике атмосферы ИФА АН ЭССР, № 6, 63 (1964).

4. Ни йлиск Херберт, Спектральный радиационный режим посева кукурузы и расчет фотосинтетически активной радиации (ФАР), Изв. АН ЭССР. Сер. физ.-матем. и техн. наук, № 3, 177 (1964).

5. Wiesner J., Der Lichtgenuss der Pflanzen, Leipzig, 1907.

6. Seybold A., Uber den Lichtgenuss der Sonnen und Schattenpflanzen, Ber. Dtsch. bot. Ges., 52, 493 (1934).

7. S e y bold A., Über den Lichtfaktor fotophysiologischer Prozesse, Jahrb. wiss. Bot., 82, 741 (1936).

8. S a uberer F. u. Härtel O., Pflanze und Strahlung, Leipzig, 1959.

9. $\mathrm{Härtel} \mathrm{O}$., Ober die richtungsabhängige Intensität des Lichtes in verschiedenen Spektralbereichen über und in Pflanzenbeständen, Wetter und Leben, 13, H. 1-2, 1 (1961).

10. N ä ge li W., Lichtmessungen im Freiland und in geschlossenen Altholzbeständen, Mitt. Schweiz. Anstalt forstl. Versuchswesen, 21, 250 (1940).

11. Алексеев В. А., К методике измерения освещенности под пологом леса, Физиол. растений, 10, вып. 2, 244 (1963).

12. А лексе ев В. А., Некоторые вопросы оптических свойств леса. Пробл. экол, и физиол. лесных растений, 1963, 47.

13. Гуляе в В. И., Компенсирующая насадка к радиометрам с полосками фильтрами, Тр. ГГО, вып. 100, 193 (1960).

14. Гу ляев В. И., Вопросы методики измерения фотосинтетически активной радиацин и об усвоении солнечной энергии некоторыми сельскохозяйственными культурами, Диссертация, Киев, 1963. 
15. Ннйлиск Херберт, Упрощенный спектрофотометр для измерення спектральных потоков рассеянной радиации, Исслед. по физике атмосферы ИФА АН ЭССР, № 3,150 (1962).

16. Л опухин Е. А., К вопросу о роли радиации в жизнедеятельности хлопчатника, Тр. ГГО, вып. 3, 14 (1949).

17. Н и йлиск Херберт, Светонзмерительная рейка для определения прямой радиации внутри посевов и растительности, Исслед. по физике атмосферы ИФА АН ЭССР, № 4, 120 (1963).

Ннститут физики и астрономии Академии наук Эстонской ССР

Поступила в редакцию 8/VI 1964

A. LAISK

\section{KIIRGUSVĂLJA STATISTILISE ISELOOMU EKSPERIMENTAALNE UURIMINE MAISIKOLVIS}

Artiklis esitatakse kiirgusvälja mõōtmise tulemused maisikülvis. Mõõdeti spektraalseid intensiivsusi lainepikkustel 482 ja $558 \mathrm{~m} \mu$ ning fotosünteetiliselt aktiivse kiirguse vooge eri kõrgustel ning eri suundades taimkatte sees.

Spetsiaalse statistilise analüsaatori abil registreeriti mõõdetava juhusliku suuruse tõenäosustiheduse funktsioon. Joonistel $1-4$ esitatakse intensiivsuste ja voogude jaotuse histogrammid, joonisel 5 vastavate keskvääruste diagrammid suundade järgi.

\section{A. LAISK}

\section{EXPERIMENTAL INVESTIGATIONS OF A STATISTIC CHARACTER OF THE RADIATION FIELD IN MAIZE CROP}

The results of some experimental investigations of the radiation field in maize crop are presented in the paper. Monochromatic intensities (482 and $558 \mathrm{m \mu}$ ) and fluxes of the photosynthetically active radiation on various levels and in various directions within plant cover were measured. Histograms of the statistical distribution of measured intensities and fluxes, presented in figs $1-4$, were recorded by means of a special statistical analyser. The diagrams of mean values are shown in fig. 5 . 